\title{
On a PH Type Stainless Steel Containing High Nitrogen and High Silicon*
}

\author{
By Masazo Okamoto** Takeshi Naito***
}

\begin{abstract}
A metallographical study has been carried out on the steel melted and cast under the 10 atmospheric pressure of nitrogen. The chemical composition of this steel is $16 \% \mathrm{Cr}-3 \% \mathrm{Si}-4 \% \mathrm{Ni}-4 \% \mathrm{Cu}-0.44 \% \mathrm{~N}-\mathrm{Bal} \mathrm{Fe}$. Various factors have been clarified to obtain a high strength $\mathrm{PH}$ type stainless steel. The results may be summarized as follows :

(1) Thorough soaking at about $1100^{\circ} \mathrm{C}$ and repeated light deformations at the temperature in the initial stage of forging are necessary to hot-work without forming cracks in the cast ingot.

(2) The microstructure of the steel water-quenched from $1100^{\circ} \mathrm{C}$ after held for $10 \mathrm{~min}$ consists of austenite having a small a mount of insoluble nitride particles. The austenite is still stable even after cooled down to $-180^{\circ} \mathrm{C}$. The higher the solution-quenching temperature, the less the amount of the insoluble nitride becomes.

(3) On tempering of the solution-quenched steel, the yield strength increases remarkably, and the ductility decreases. To make the steel strong and tough, it is adequate to hot-cold work during the tempering at $700^{\circ} \mathrm{C}$ of the steel waterquenched from $1100^{\circ} \mathrm{C}$ and subsequently reheat at $450^{\circ} \mathrm{C}$ for $60 \mathrm{~min}$ to relieve the internal stress. When $33 \%$ hot-cold rolled by the above treatment, the steel shows such an excellent final tensile properties as $\sigma_{B}=129 \sim 121 \mathrm{~kg} / \mathrm{mm}^{2}, \sigma_{S}=109 \sim 116$ $\mathrm{kg} / \mathrm{mm}^{2}$ and $\delta=22 \sim 23 \%$.
\end{abstract}

(Received July 13, 1964)

\section{Introduction}

The effect of silicon addition to the 17-4 PH type stainless steel had been clarified by one of the authors in a previous paper ${ }^{(1)}$ from the metallographic point of view. The present paper deals with the phase changes and improvement of mechanical properties in one of the $\mathrm{Si}$ containing $17-4 \mathrm{PH}$ type stainless steel by heat-treat-

* This paper was published in the Journal of the Japan Institute of Metals, 27 (1963), 519.

** Department of Metallurgical Engineering, Tokyo Institute of Technology, Tokyo, Japan.

**** Komatsu Manufacturing Co., Ltd., Awazu Plant, Ishikawa, Japan.

(1) M. Okamoto : Trans. JIM, 3 (1962), 51. ment and hot-cold working. This steel was melted and cast at a 10-atmospheric pressure of nitrogen and had the chemical composition of $16 \% \mathrm{Cr}-3 \% \mathrm{Si}-4 \%$ $\mathrm{Ni}-4 \% \mathrm{Cu}-0.44 \% \mathrm{~N}-\mathrm{Bal} \mathrm{Fe}$.

\section{Preparation of the Specimen}

The high-pressure melting furnace used for melting and casting of the steel was a $15 \mathrm{kVA}$ high-frequency induction furnace having a structure similar to that of the common inside heatinng type vacuum-melting furnace, except that the vacuum tank body and multiple vacuum-sealing parts were so designed as to stand an inner pressure up to $15 \mathrm{~atm}$. The vacuum tank 
was of a horizontal cylinder type of about $800 \mathrm{~mm}$ in both diameter and length and equipped with a 1,500 $1 /$ min rotary oil pump, a $3801 / \mathrm{sec}$ oil diffusion ejector pump and a $1900 \mathrm{l} / \mathrm{sec}$ oil diffusion pump so as to replace the air in the tank with nitrogen. The melting capacity per charge was $5 \mathrm{~kg}$ and a crucible of fused magnesia with an inside diameter of $85 \mathrm{~mm}$ was used. The depth of the $5 \mathrm{~kg}$ molten steel was about $100 \mathrm{~mm}$.

Chemical elements for melting such as $\mathrm{Fe}, \mathrm{Cr}, \mathrm{Ni}$ and $\mathrm{Cu}$ were all electrolytic high-purity elements, while $\mathrm{Si}$ was added as the simple metal. $\mathrm{Fe}, \mathrm{Cr}$ and $\mathrm{Ni}$ were previously charged into the crucible, melted in a vacuum of $1 \times 10^{-3} \mathrm{~mm} \mathrm{Hg}$ and heated to about $1500^{\circ} \mathrm{C}$. Then high-purity nitrogen was introduced to make $1 \mathrm{~atm}$. Next, $\mathrm{Mn}, \mathrm{Si}$ and $\mathrm{Cu}$ were added and again nitrogen gas was introdused. When the gas reached the 10 atmospheric pressure, the metal was kept for 30 min and then cast into a mould in the atmosphere of the same pres. sure. The mould, made of copper, was of the square type with the dimension of $62 \mathrm{~mm}$ in the upper side, $54 \mathrm{~mm}$ in the lower side, $180 \mathrm{~mm}$ in height and $45 \mathrm{~mm}$ in wall-thickness. The total time required for melting and casting was about $55 \mathrm{~min}$.

After thorough soaking at $1100^{\circ} \sim 1000^{\circ} \mathrm{C}$, the cast ingot was forged into a $15 \mathrm{~mm}$ square billet (forging ratio : 16) and subsequently hot-rolled to the thickness of $7.2 \mathrm{~mm}$ at about $1100^{\circ} \mathrm{C} \sim 1000^{\circ} \mathrm{C}$. Hot-woking of the cast ingot was not easy and therefore both thorough soaking at about $1100^{\circ} \mathrm{C}$ and repeated light deformations at the temperature in the initial stage of forging were necessary to hot-work without forming cracks in the cast ingot. The chemical composition of the steel melted is shown in Table 1.

Table 1 Chemical composition $(\%)$ of the alloy.

\begin{tabular}{c|c|c|c|c|c|c|c|c|c}
\hline & $\mathrm{C}$ & $\mathrm{Si}$ & $\mathrm{Mn}$ & $\mathrm{P}$ & $\mathrm{S}$ & $\mathrm{Ni}$ & $\mathrm{Cu}$ & $\mathrm{Cr}$ & Ntotal \\
\hline $30 \mathrm{~S}-10$ & 0.004 & 2.80 & 0.47 & 0.011 & 0.010 & 4.35 & 4.01 & 15.94 & 0.44 \\
\hline
\end{tabular}

\section{Experimental Results and Discussion}

\section{Change in the nitrogen concentration of steel by high-temperature heating}

The behavior of nitrogen in the steel during heating to a high-temperature in various atmospheres was investigated using a thermobalance. Scraps (about 100 $200 \mathrm{mesh}$ ) of the forged billet granulated by filing were used as the specimens. The curve of weight change during heating of the specimen in vacuum is shown in Fig. 1. The weight decrease which indicates denitrogenization was found to begin from around $200^{\circ} \mathrm{C}$ during heating in vacuum. The amount of denitrogenization increased with increasing temperature, until a subsequent holding up to $30 \mathrm{~min}$ at $1100^{\circ} \mathrm{C}$.

The ratio in weight change due to the heating was calculated from equation $n=\left[\left(W-W^{\prime}\right) / W\right] \cdot 100$, where $W$ and $W^{\prime}$ were weights of the specimen before and after the heating. The $n$ value calculated from data shown in Fig. 1 was $-0.32 \%$, which indicated that about 73 .
$\%(=0.32 / 0.44 \cdot 100)$ of nitrogen initially contained in the specimen was removed during heating in vacuum at $1100^{\circ} \mathrm{C}$ for $60 \mathrm{~min}$. During heating in the 1 atmospheric pressure of nitrogen, however, as shown in Fig. 2, a rapid increase in weight was found to begin in the vi-

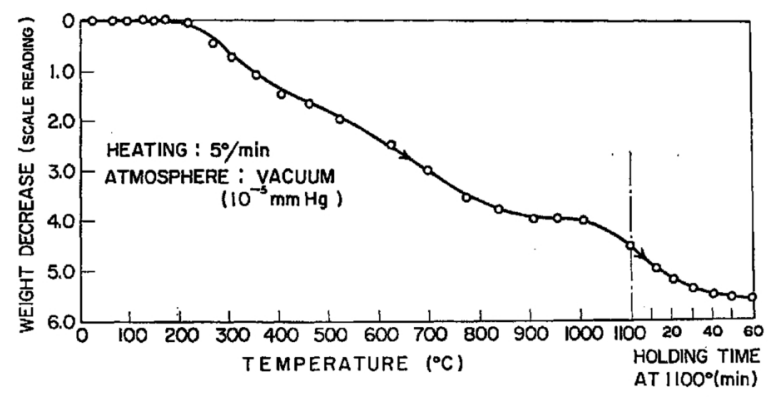

Fig. 1 Weight change during heating in vaccum of the granular specimen as forged.

$H_{v}$

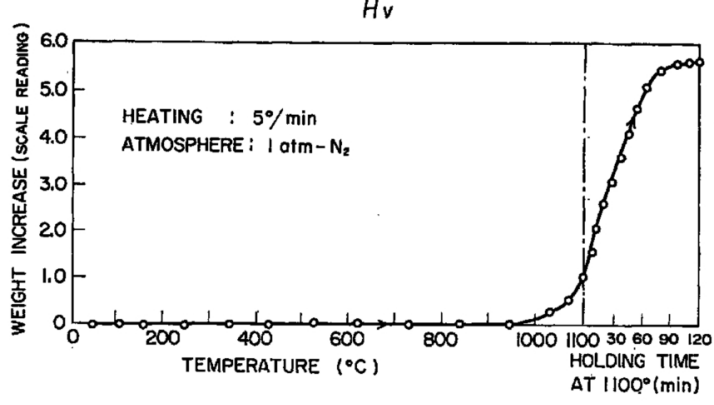

Fig. 2 Weight change during heating in 1 atm $-\mathrm{N}_{2}$ of the granular specimen as forged.

cinity of $950^{\circ} \mathrm{C}$, and after holding for $120 \mathrm{~min}$ at 1100 ${ }^{\circ} \mathrm{C}$, the ratio in weight change, $n$, was calculated to be $+0.58 \%$; that is, the granular specimens were found to absorb nitrogen at temperatures higher than $950^{\circ} \mathrm{C}$ under the 1 atmospheric pressure of nitrogen. The curve of weight change during heating in air is shown in Fig. 3. The weight increase with temperature was

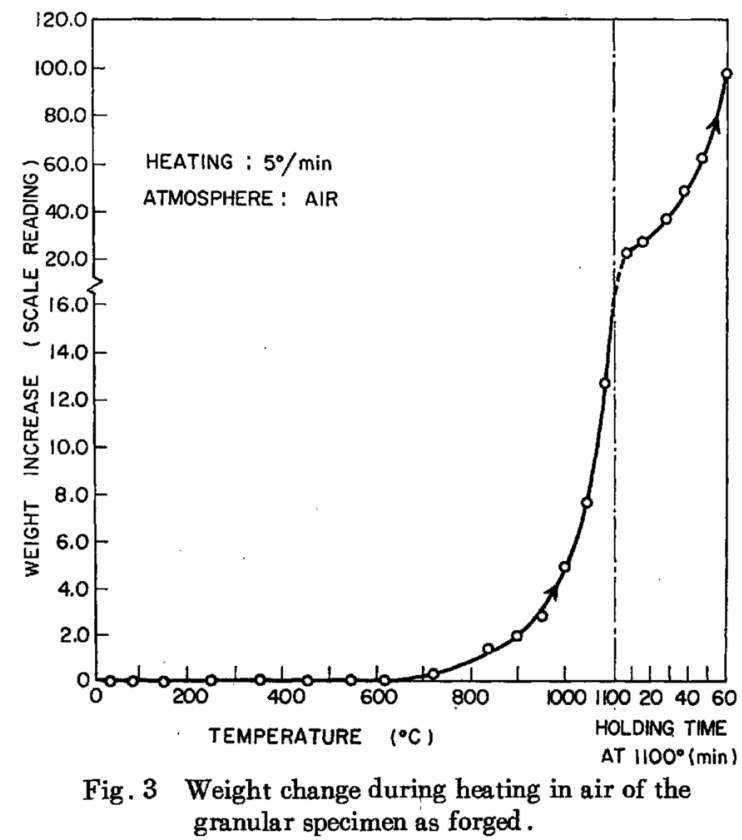

thought to be due to the nitrogen-absorption and oxidation which occurred almost simultaneously. It was found 
that the nitrogen-absorption and oxidation of the bulk specimens were not so strong as those of the granular specimens.

\section{Microstructure and hardness of solution treated specimens}

Photo. 1 shows a microstructure of the specimen

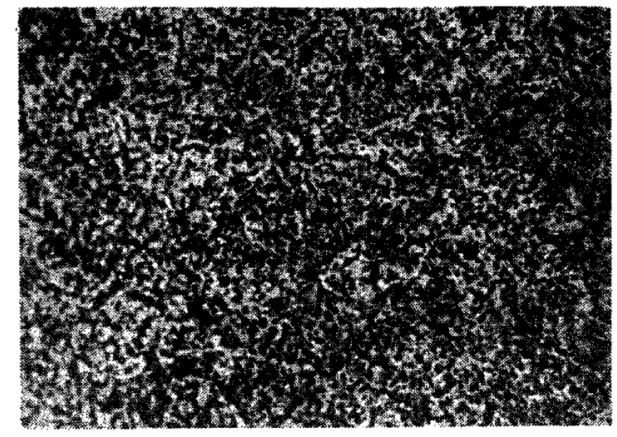

$$
\times 400
$$

Photo. 1 Microstructure of alloy slow cooled from $700^{\circ} \mathrm{C}$ after held for $30 \mathrm{~min}$. Etched electrolytically by $10 \%$ oxalic acid.

which was slow cooled after being held at $700^{\circ} \mathrm{C}$ for 30 min, in which many precipitation particles embeded in the $\alpha$ iron matrix could be observed. Due to heating at $950^{\circ} \mathrm{C}$ for $10 \mathrm{~min}$, the greater part of the matrix converted into austenite as shown in Photo. 2 , but many of the precipitation particles remained unchanged. At the temperature of $1100^{\circ} \mathrm{C}$, the structure of the steel came to consist only of almost single austenite as shown in Photo. 3.

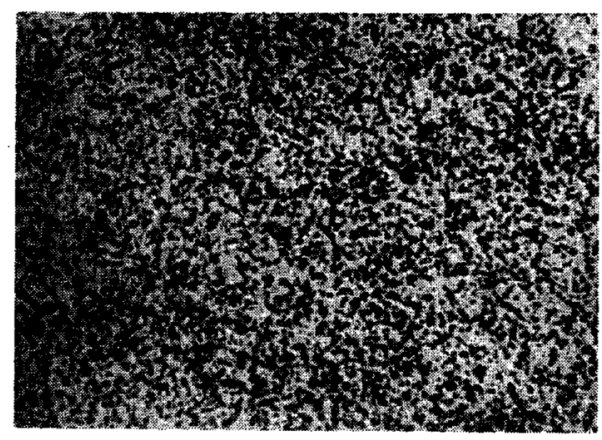

$\times 400$

Photo. 2 Microstructure of alloy water quenched from $950^{\circ} \mathrm{C}$ after held for $10 \mathrm{~min}$. Etched electrolytically by $10 \%$ oxalic acid.

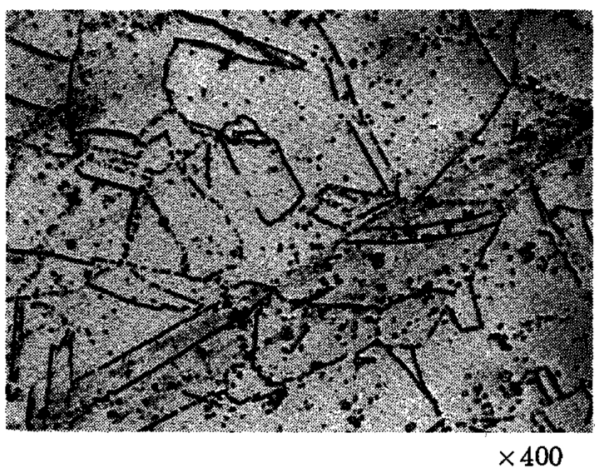

Photo. 3 Microstructure of alloy water quenched from $1100^{\circ} \mathrm{C}$ after held for $10 \mathrm{~min}_{\mathrm{s}}$. Etched electrolytically by $10 \%$ oxalic acid,
Fig. 4 is an illustration of the relationship between the solution treatment temperatures and the Vickers hardness of the specimen water-quenched from that temperature. The hardness after solution quenching decreased with increasing temperature because of the

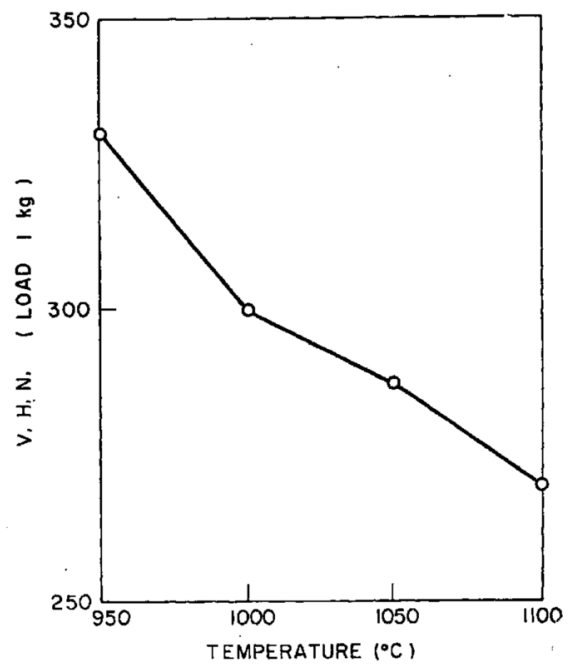

Fig. 4 Vickers hardness of the specimen water quenched from various temperatures.

dissolution of nitride particles into the matrix, and the austenite became more stable with increasing temperature.

\section{Phase change by heat-treatment}

Fig. 5 shows a differential dilatation curve of the specimen which was slow cooled after being held at 700

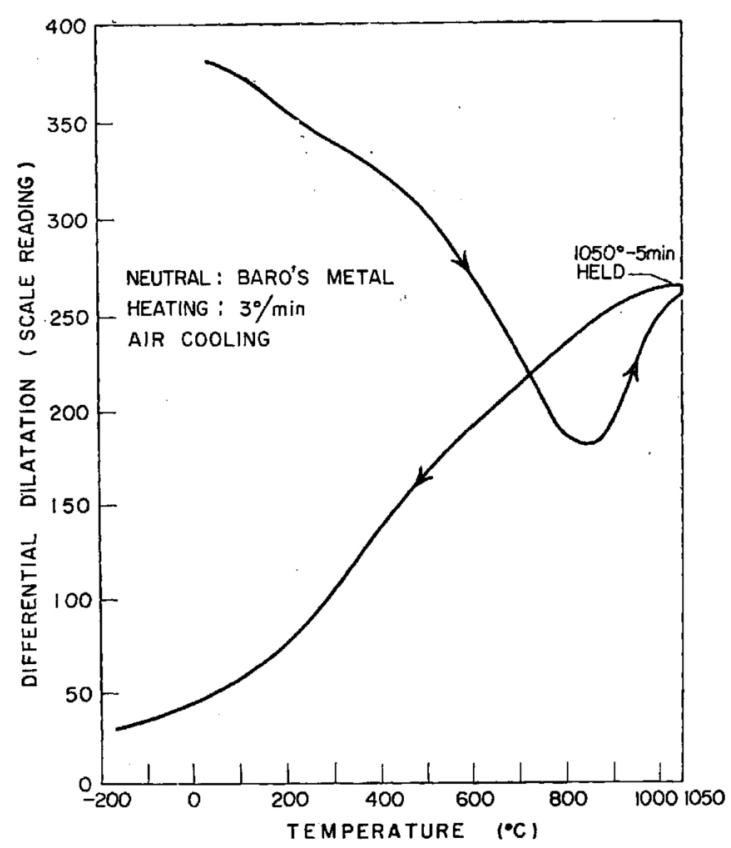

Fig. 5 Differential dilatation curve of the specimen during slow heating, air cooling and subzero cooling.

${ }^{\circ} \mathrm{C}$ for $30 \mathrm{~min}$. On the heating curve, a remarkable contraction which occurs at a temperature above $500^{\circ} \mathrm{C}$ seems to be due to the precipitation of nitride and the $\alpha \rightarrow \gamma$ transformation, and the $A_{3}$ ending temperature where the $\alpha$ phase is completely transformed into the $\gamma$ 
phase can be found at about $820^{\circ} \mathrm{C}$. Above the temperature of $820^{\circ} \mathrm{C}$, a conspicuous expansion is observed due to the dissolution of nitride particles into the austenite matrix. Austenite thus formed is so stable that it does not transform into martensite even if cooled down to $-195^{\circ} \mathrm{C}$ after water-quenched from $1050^{\circ} \mathrm{C}$. Fig. 6 contraction which occurred during a subsequent holding at $700^{\circ} \mathrm{C}$, was considered due to a competition of the expansion caused by the $\gamma \rightarrow \alpha$ transformation and the contraction by the precipitation. One can confirm the for mation of the ferrite as shown in Photo. 4 and Photo. 5. The amount of the ferrite increased with the holding time.

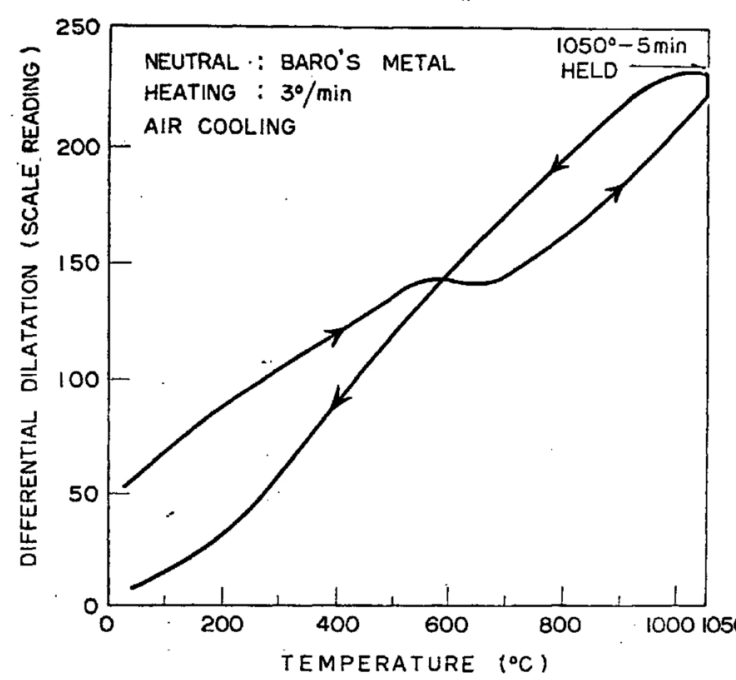

Fig. 6 Differential dilatation curve during slow heating and air cooling of the specimen water quenched from $1050^{\circ} \mathrm{C}$ after held for 10 minutes.

shows a differential dilatation curve during slow heating and air cooling of the specimen which was water-quenched from $1050^{\circ} \mathrm{C}$ after being held for $10 \mathrm{~min}$. A considerable contraction can be seen in the temperature range from $550^{\circ}$ to $630^{\circ} \mathrm{C}$ on the heating curve. This contraction is obviously caused by the nitride precipitation from the austenite matrix. Austenite formed by holding at $1050^{\circ} \mathrm{C}$ for $5 \mathrm{~min}$ does not transform into martensite by air cooling from that temperatur as shown in Fig. 5. When a bulk specimen was subzero-cooled into a liquid-nitrogen bath after water-quenched from $1100^{\circ} \mathrm{C}$, austenite remained unchanged without decomposing into martensite. When a specimen was subjected to plastic deformation by rolling at room temperature, a part of the austenite transformed into martensite and the specimen showed a strong ferro-magnetic property. From the above results, it can be concluded that the Md point of austenite in the steel after solution-quenched from $1100^{\circ} \mathrm{C}$ lies above room temperature. Differential dilatation curves of the specimen air cooled or subzerocooled after tempering at $500^{\circ}, 550^{\circ}$ and $700^{\circ} \mathrm{C}$ for various periods of time are shown in Fig. 7. The contraction of the specimens, caused by precipitation from austenite, during holding at $500^{\circ}$ and $550^{\circ} \mathrm{C}$ increased with the increasing temperature and tempering time. However, during the $700^{\circ} \mathrm{C}$ tempering, as shown in the figure, the dilatation curve on heating indicates a slight contraction at $500^{\circ} \sim 650^{\circ} \mathrm{C}$, and subsequently changes again into expansion above $650^{\circ} \mathrm{C}$, followed by a contraction during holding at $700^{\circ} \mathrm{C}$. At the temperature of $500^{\circ} \sim 550^{\circ} \mathrm{C}$, the precipitation from austenite seemed to occur easily, but above that temperature the amount of precipitation decreases. On further heating alloying elements were depleted in the austenite by precipitation and the austenite began to decompose into ferrite, resulting in an expansion. A small and gradual

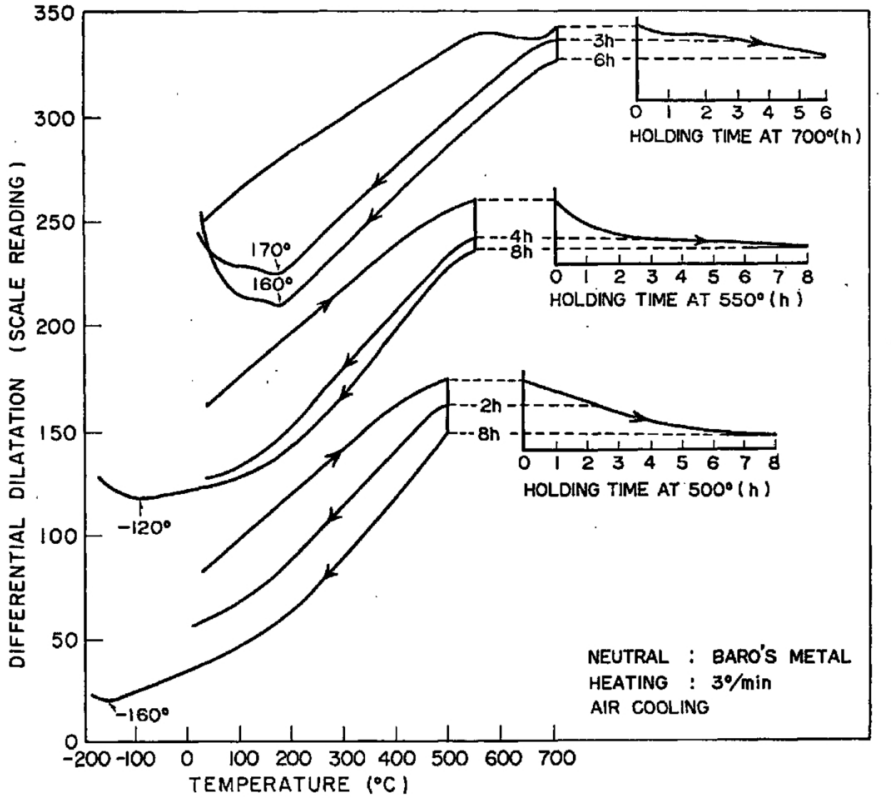

Fig. 7 Differential dilatation curves of specimens air-or subzero-cooled from various temperatures after held for various times.

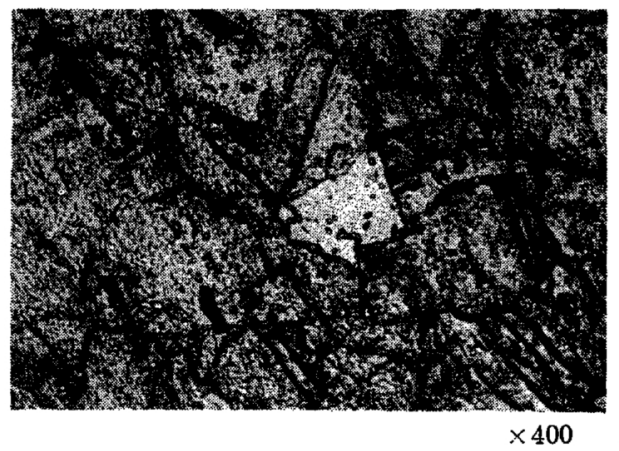

Photo. 4 Microstructure of alloy air cooled from $700^{\circ} \mathrm{C}$ after held for $3 \mathrm{hr}$. Etched electrolytically by $10 \%$ oxalic acid.

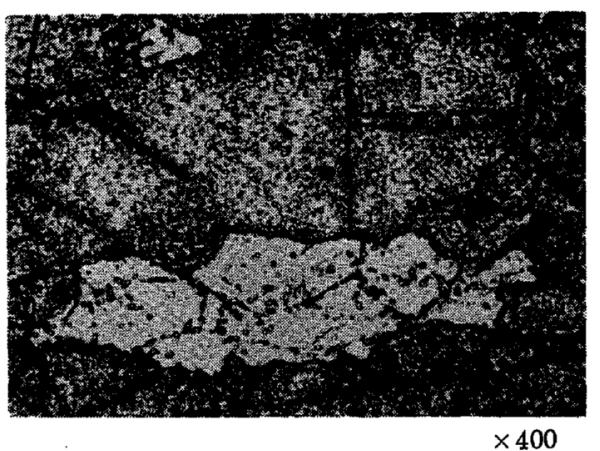

Photo. 5 Microstructure of alloy air cooled from $700^{\circ} \mathrm{C}$ after held for $6 \mathrm{hr}$. Etched electrolytically by $10 \%$ oxalic acid.

The precipitant was supposed to be $\mathrm{Cr}_{2} \mathrm{~N}$ and a $\mathrm{Cu}$-rich solid solution. By subzero-cooling of the specimens which were air cooled after being held for $8 \mathrm{hr}$ 
at $500^{\circ} \mathrm{C}$, the austenite began to transform into martensite at $-160^{\circ} \mathrm{C}$. When the specimen was held for $8 \mathrm{hr}$ at $550^{\circ} \mathrm{C}$, the martensitic transformation began at $-120^{\circ} \mathrm{C}$ by subsequent subzero-cooling. By air-cooling after holding for 3 and $6 \mathrm{hr}$ at $700^{\circ} \mathrm{C}$, the remaining austenite began to transform into martensite at $160^{\circ} \mathrm{C}$ and $170^{\circ} \mathrm{C}$, being considerably higher than room temperature. Although the difference in Ms points of the specimens air-cooled after holding for 3 and $6 \mathrm{hr}$ was very small, it was confirmed that the specimen held for $6 \mathrm{hr}$ contained a considerably larger amount of martensite than that held for $3 \mathrm{hr}$ after air-cooling to room temperature.

\section{Improvement in mechanical properties by beat treatment with hot-cold working}

Fig. 8 shows hardness changes of specimens by tempering times at $450^{\circ}, 500^{\circ}, 550^{\circ}$ and $700^{\circ} \mathrm{C}$ after

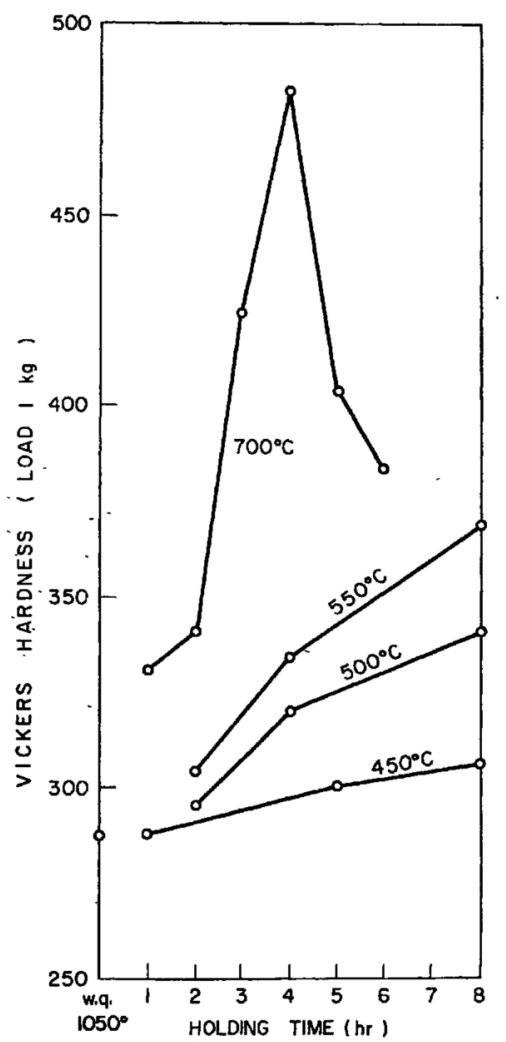

Fig. 8 Vickers hardness of specimens air cooled from various temperatures after held for various hours.

$1050^{\circ} \mathrm{C}$ solution treatment. The hardening by tempering below $550^{\circ} \mathrm{C}$ was simply caused by the precipitation, where as a remarkable hardening by tempering at a temperature as high as $700^{\circ} \mathrm{C}$ would be attributed to both the precipitation and the martensite transformation during air-cooling. The cause of the above transformation was due to the depletion of alloying elements in the retained austenite as a result of the increasing amount of the precipitant by high-temperature aging. Due to the aging at $700^{\circ} \mathrm{C}$, the hardness of the specimen increased and attained a maximum with the tempering time up to $4 \mathrm{hr}$, and then decreased with the aging time. The reason why the hardness curve at $700^{\circ} \mathrm{C}$ showed the maximums may be considered as follows; one is the growth of the precipitant, the other is the amount of martensite decreased by the $\gamma \rightarrow \alpha$ transformation at the tempering of $700^{\circ} \mathrm{C}$.

Tensile properties of the plate-form specimens were investigated by aging at $700^{\circ} \mathrm{C}$ for 2,3 , or $4 \mathrm{hr}$ and reheating to $450^{\circ} \mathrm{C}$ for 1,4 or $6 \mathrm{hr}$ after the solution treatment at $1100^{\circ} \mathrm{C}$ for $10 \mathrm{~min}$. The reheating treatment at $450^{\circ} \mathrm{C}$ was added to the heat treatment process in order to relieve the stress caused by the newly formed martensite during air cooling from $700^{\circ} \mathrm{C}$. The size of the specimens used was $3 \mathrm{~mm}$ in thickness, $5 \mathrm{~mm}$ in width and $30 \mathrm{~mm}$ in length. Tensile properties of the alloy are shown in Table 2. Comparing the values

Table 2 Tensile properties of the alloy air cooled from $700^{\circ} \mathrm{C}$ after held for various times and subsequently reheated at $450^{\circ} \mathrm{C}$ for various times.

\begin{tabular}{c|c|c|c|c}
\hline $\begin{array}{r}\text { Holding time at } \\
450^{\circ} \mathrm{C}(\mathrm{hr})\end{array}$ & $\mathrm{kg} / \mathrm{mm}^{2}, \%$ & 1 & 4 & 6 \\
& & & & \\
Holding & & & & \\
time at $700^{\circ} \mathrm{C}(\mathrm{hr})$ & $\sigma_{B}$ & - & - & 94.5 \\
\hline & $\sigma_{S}$ & - & - & 74.5 \\
& $\delta$ & - & - & 24.0 \\
\hline \multirow{2}{*}{3} & $\sigma_{B}$ & 93.0 & 96.5 & - \\
& $\sigma_{S}$ & 80.0 & 75.5 & - \\
& $\delta$ & 18.5 & 15.4 & - \\
\hline & $\sigma_{B}$ & 87.0 & 85.5 & - \\
& $\sigma_{S}$ & 75.4 & 75.0 & - \\
\hline
\end{tabular}

shown in Table 2 with those in the solution-quenched state, it is evident that by the tempering, the strength increases and the elongation decreases. Both the strength and the elongation increased with decreasing holding time at $700^{\circ} \mathrm{C}$. On the other hand, when the formation of $\alpha$ from $\gamma$ by a diffusion transformation proceeded with a prolonged holding at $700^{\circ} \mathrm{C}$, not only the decrease in tensile strength but also a remarkable elongation decrease were observed. It may be concluded form these results that by a simple combination of solution quenching and tempering, it is impossible to produce a sufficiently strong and tough stainless steel. Then, it was examined to apply a $33 \%$ hot-cold rolling during tempering at the temperatures of $550^{\circ}, 600^{\circ}, 650^{\circ}$ or $700^{\circ} \mathrm{C}$ to the steel solution treated from $1100^{\circ} \mathrm{C}$. A technique used in this examination was as follows : The solutionquenched specimens were dipped into a lead bath held at the various temperatures stated above, and then rolled at these temferatures. In all the cases, the rolling carried out so as to complete for $10 \mathrm{~min}$ and by 6 passes. When rolling was carried out, two different combinations were examined of the rolling with aging at these temperatures; one was the rolling after dipping in a lead bath for $3 \mathrm{~min}$ (namely, the earlier stage rolling) and subsequent aging for $50 \mathrm{~min}$, the other was the rolling after prior aging for $50 \mathrm{~min}$ (the later stage rolling). Finally, all the specimens were air-cooled from each temperature.

Hardness and tensile tests and measurments of $\alpha \%$ by a ferrite indicator were conducted on the specimens hot-cold worked. The results are given in Fig.9. When the specimen rolled in the earlier stage, the diffusion and 
precipitation of solute atoms in the aging were promoted by the residual strain resulting from the rolling, and thus the concentration of the alloying elements in austenite became low. As a result, more austenite decomposed into martensite by air-cooling after the aging.

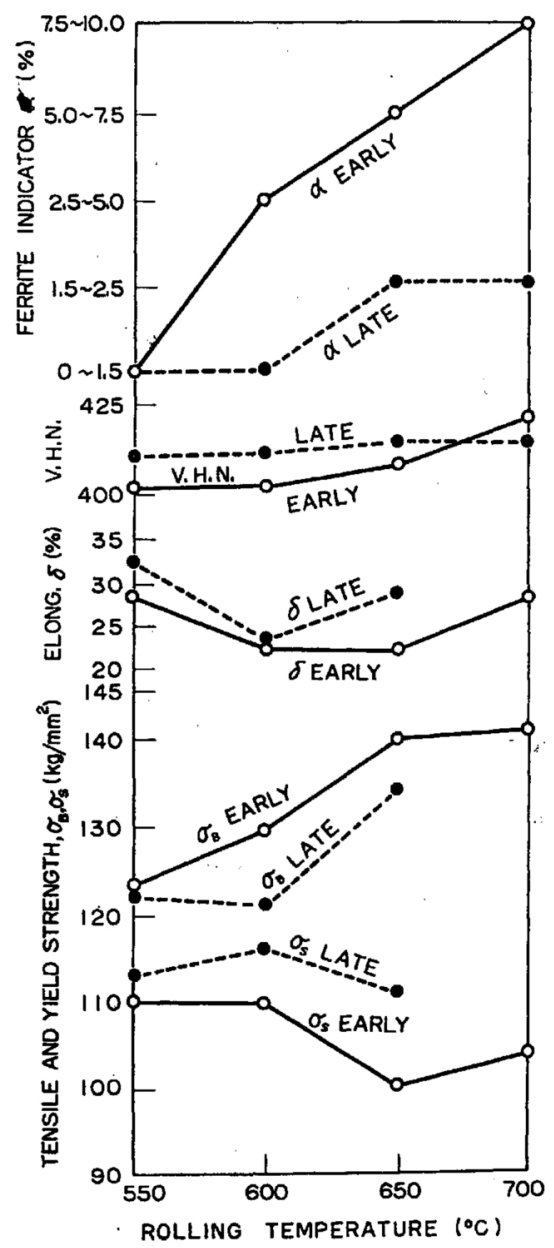

Fig. 9 Some mechanical properties of specimens hot-cold rolled $33 \%$ in the earlier stage or in the later stage during holding 60 min at various rolling temperatures and subsequently reheated at $450^{\circ} \mathrm{C}$ for 60 min.

Therefore, the specimen hot-cold rolled in the earlier stage showed a stronger magnetism than the hot-cold rolled one in the later stage of rolling, and this tendency became remarkable with rise in the temperature of rolling. The hardness of the specimens also increased with increasing temperature of hot-cold working in the earlier stage. This might be attributed to the martensitization caused by the increasing precipitation. That is, the hardening trend by hot-cold rolling, becomes small due to stress relief during aging. However, the hardeness of the specimen coold from aging temperature increased with the amount of martensite due to the reduced concentration of alloying elements in austenite, because the formation of precipitation from austenite is larger than softening due to stress relief during aging after rolling. On the other hand, by the later stage rolling, the hardness of the specimens did not change appreciably with the rolling temperature : It was probable that with the increasing temperature of rolling, the precipitation and martensitization were promoted only slightly because of the lack of the earlier stage rolling, and that the work-hardening decreased with increasing temperature. In general, the tensile properties of the steel hot-cold worked were superior to that without hot-cold working. The specimens rolled in the earlier stage had a higher tensile

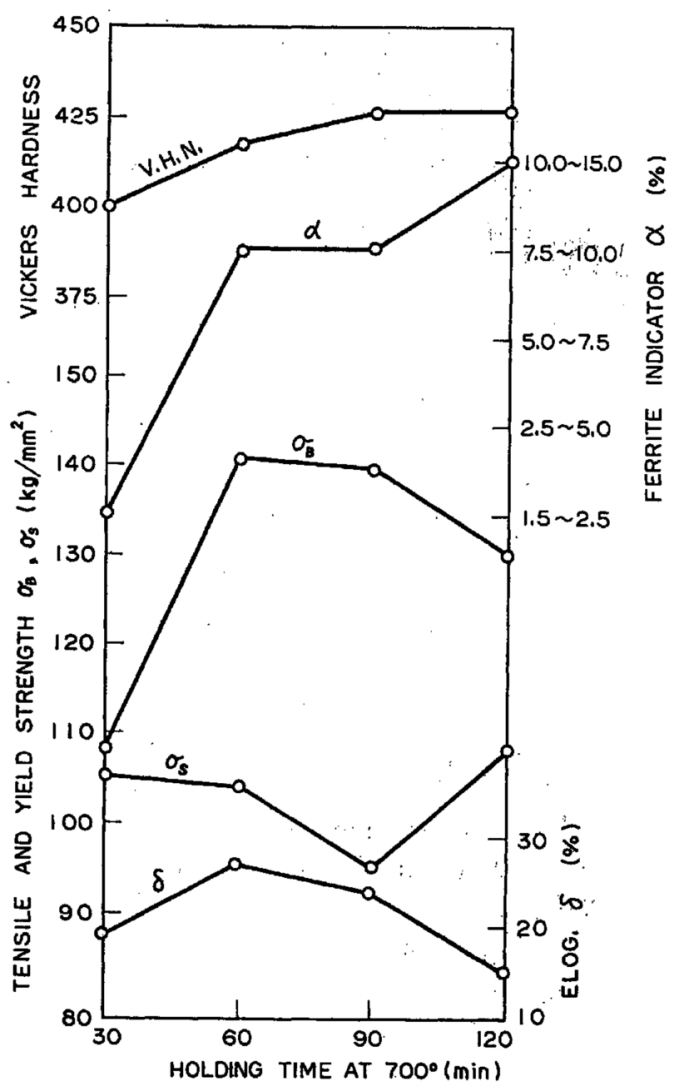

Fig.10 Some mechanical properties of specimens rolled $33 \%$ at $700^{\circ} \mathrm{C}$ in the earlier stage during the holdings and subsequently reheated at $450^{\circ} \mathrm{C}$ for $60 \mathrm{~min}$.

strength, lower yield strength and smaller elongation than that rolled in the later stage. Moreover, the maximum value of the yield strength was obtained by the rolling in the later stage at $600^{\circ} \mathrm{C}$, and in this rolling condition of the specimen showed such tensile properties as $\sigma_{B}=121 \mathrm{~kg} / \mathrm{mm}^{2}, \sigma_{S}=116 \mathrm{~kg} / \mathrm{mm}^{2}$ and $\delta=22 \%$. In Fig. 10 are shown changes in mechanical and magnetic properties of the steel with increasing holding time at $700^{\circ} \mathrm{C}$ after the $33 \%$ rolling in the earlier stage of the tempering at the same temperature. It is obvious from the figure that both the amount of ferrite and the hardness of the steel increase with increasing holding time. But the tensile strength of the steel attained a maximum at the holding time of 60 to $90 \mathrm{~min}$ at $700^{\circ} \mathrm{C}$, and thereafter decreased with prolonged holding. It was interesting that the elongation of the steel showed a similar behavior as the tensile strength. The relation between the yield strength and the holding time at 700 ${ }^{\circ} \mathrm{C}$ was not clear. Photo. 6 shows a microstructure of the alloy air cooled from $450^{\circ} \mathrm{C}$ after a $33 \%$ hot-cold rolling in the earlier stage during holding for $60 \mathrm{~min}$ at $700^{\circ} \mathrm{C}$. It was apparent that a greater part of the austenite in this specimen transformed into martensite, because the specimen showed a considerably larger amount of precipitation, a higher hardness and a stronger magnetism than that in the solution quenched state. The 
existence of the martensite, however, was difficult to be confirmed microscopically. It can be concluded from the above results that an adequate treatment to give strength and toughness to this steel will be as follows : Water-quenching from $1100^{\circ} \mathrm{C}$ after holding for $10 \mathrm{~min}$,

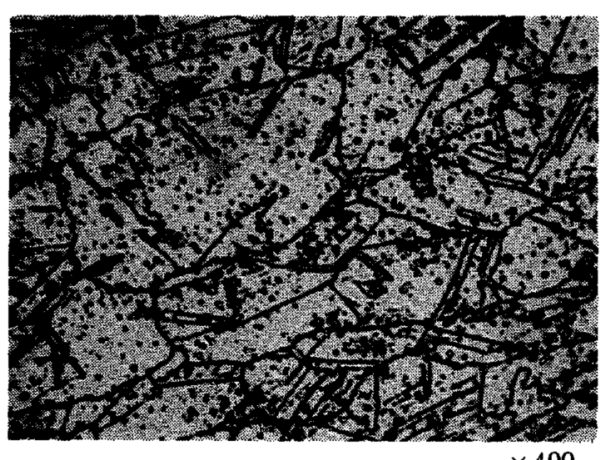

Photo. 6 Microstructure of the alloy air cooled from $450^{\circ} \mathrm{C}$ after hot-cold rolled $33 \%$ in the earlier stage during holding for $60 \mathrm{~min}$ at $700^{\circ} \mathrm{C}$. Etched electrolytically by $10 \%$ oxalic acid.

$\rightarrow$ hot-cold working in the earlier stage during holding for $60 \mathrm{~min}$ at $700^{\circ} \mathrm{C} \rightarrow$ air cooling, $\rightarrow$ stıess-relief tempering at $450^{\circ} \mathrm{C}$ for $60 \mathrm{~min} \rightarrow$ air cooling. It was also made clear that the hot-cold working in the later stage was more desirable to obtain a particularly high yield strength.

As already noted, the application of the heat-treatment with the hot-cold working would enable to produce a steel with excellent mechanical properties, (tensile strength ; $140 \mathrm{~kg} / \mathrm{mm}^{2}$, yield strength ; $108 \mathrm{~kg} / \mathrm{mm}^{2}$ elongation; $27 \%$ and Vickers hardness ; 4I5). The microstructure of the steel in this condition consists of a small amount of tempered martensite, a great ceal of austenite, and disfersed precipitants of $\mathrm{Cr}_{2} \mathrm{~N}$ and the Cu-rich phase.

\section{Summary}

A metallographic study has deen carried out on the steel of $16 \% \mathrm{Cr}-3 \% \mathrm{Si}-4 \% \mathrm{Ni}-4 \% \mathrm{Cu}-0.44 \% \mathrm{~N}-\mathrm{Bal}$ Fe which had been melted and cast under the 10 atmospheric pressure of nitrogen, and various factors have been clarified to obtain a high strength $\mathrm{PH}$ type stainless steel. The results are summarized as follows :

(1) Thorough soaking at about $1100^{\circ} \mathrm{C}$ and repeated light deformations at the temperature in the initial stage of the forging are necessary to hot-work without forming cracks in the cast ingot.

(2) The variation in the nitrogen concentration occurs on the surface of the steel due to heating atmospheres; in the heating in vacuum and in argon-the denitrogenization, and in the heating in one atmospheric pressure of nitrogen-the nitrogen absorption. The weight increase due to the heating in air arises from both the oxidation and the nitrogen ahsorption on the surface of the steel.

(3) The microstructure of the steel water-quenched from $1100^{\circ} \mathrm{C}$ after held for $10 \mathrm{~min}$ consists of austenite having a small amount of insoluble nitride particles. The austenite is still stable even when cooled down to$180^{\circ} \mathrm{C}$. The higher the solution-quenching temperature, the less the amount of the insoluble nitride becomes.

(4) precipitants, probably $\mathrm{Cr}_{2} \mathrm{~N}$ and a $\mathrm{Cu}$-rich solid solution are formed in the austenite by the tempering at $500^{\circ} \sim 550^{\circ} \mathrm{C}$ after the solution-quenching. If the tempering at $500^{\circ} \sim 550^{\circ} \mathrm{C}$ is prolonged, a small amount of martensite is formed below $-100^{\circ} \mathrm{C}$ by the subsequent subzero-cooling after the tempering. Both the precipitation and the ferrite formation from the austenite are found to proceed simultaneously during the tempering at $700^{\circ} \mathrm{C}$. By the subsequent cooling from the temper ing temperature, the remaining austenite transforms into martensite at temperatures considerably higher than room temperature.

(5) On tempering of the solution-quenched steel, the yield strength increases remarkably, while the ductility decreases. To make the steel strong and tough, it is adequate to hot-cold work during the tempering at 600 ${ }^{\circ} \mathrm{C}$ of the steel water-quenched from $1100^{\circ} \mathrm{C}$ and subsequently to reheat at $450^{\circ} \mathrm{C}$ for $60 \mathrm{~min}$ so as to relieve the internal stress. When $33 \%$ hot-cold rolled in the above treatment, the final tensile properties are found to be $\sigma_{B}=129 \sim 121 \mathrm{~kg} / \mathrm{mm}^{2}, \sigma_{S}=109 \sim 116 \mathrm{~kg} / \mathrm{mm}^{2}$ and $\delta=22 \sim 23 \%$. Stronger magnetism and lower $\sigma_{S}$ are obtained by the hot-cold working in the earlier stage of tempering. 